\title{
Functional status and use of healthcare facilities in long-term survivors of transient ischaemic attack or minor ischaemic stroke
}

\author{
I van Wiik, E Lindeman, L J Kappelle, J van Gijn, P J Koudstaal, J W Gorter, A Algra, \\ for the LiLAC Study Group*
}

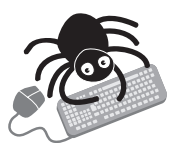

J Neurol Neurosurg Psychiatry 2006;77:1238-1243. doi: 10.1136/jnnp.2006.089391

Additional table data are provided online at http://www.jnnp.com/ supplemental

See end of article for authors' affiliations

Correspondence to: A Algra, Julius Centre, University Medical Centre Utrecht, Str 6.131, PO Box 85500, 3508 GA Utrecht The Netherlands; a.algra@umcutrecht.nl

Received 26 January 2006 Revised version received 3 May 2006

Accepted 4 May 2006 Published Online First 30 May 2006

\begin{abstract}
Background: Stroke may have a major effect on survivors and on the healthcare system.
Aims: To study the functional status and use of healthcare facilities in long-term survivors of a transient ischaemic attack (TIA) or minor ischaemic stroke (MIS) and evaluate associations with baseline and followup characteristics.

Methods: Follow-up of patients who had participated in the Dutch TIA Trial or the European Atrial Fibrillation Trial was extended to a mean period of 15.6 years. Patients were interviewed through a postal questionnaire $(n=468)$ and a sample of this group was also interviewed at home $(n=198)$. Demographic data, information on comorbidity, functional status (Barthel Index, Frenchay Activities Index and modified Rankin Scale) and use of healthcare facilities were recorded.

Results: About one third of the survivors interviewed at home experienced any residual disability and $26 \%$ were moderately to severely handicapped. Factors associated with poor functional status were advanced age and the presence of any infarct on a baseline computed tomography scan, the recurrence of a new major stroke or the presence of comorbidity of locomotion. One third of survivors used any kind of professional care, which was predominantly related to the functional status at follow-up.

Conclusions: Recurrent stroke and the presence of comorbidity of locomotion are important determinants of long-term disability of survivors of a TIA or an MIS, which, in turn, is strongly associated with the longterm use of professional care. The need for measuring comorbidity with regard to functional status is recommended in research on stroke outcome.
\end{abstract}

A s mortality due to stroke decreases, the number of stroke survivors increases, and this is likely to have a growing effect on the healthcare system. Patients with no or minor sequelae from a transient ischaemic attack (TIA) or minor ischaemic stroke (MIS) are usually discharged home and are less often studied than those with a major stroke. From a previous study, however, we learnt that these patients with a "minor stroke" are exposed to a continuous high risk of recurrent major events (stroke, myocardial infarction or vascular death) even in the long term. ${ }^{1}$ Information on functional status long after a TIA or an MIS has occurred is scarce. The few studies that followed up patients for more than 10 years describe survival and, in some cases, the risk of new events..$^{1-4}$ Assessing activities and participation of these patients is important in determining quality of life $\mathrm{e}^{5}$ and use of healthcare facilities.

Previous studies on long-term functioning of patients with stroke applied only the Barthel Index and the (modified) Rankin Scale (mRS), ${ }^{78}$ or no standardised instruments at all. ${ }^{9-12}$ The Barthel Index and mRS measure important dimensions of stroke-related constraints of activity, but both have definite limitations. The Barthel Index measures only the basic activities of daily living in the home and has a profound ceiling effect, especially in people with mild or moderate stroke, whereas the mRS predominantly reflects physical dependence and does not explicitly assess psychosocial functioning.

To clarify the factors that improve or deteriorate functional capacity, it is important to differentiate the effects of stroke from those of ageing. ${ }^{10}$ It is well known that patients with stroke, who are often elderly people, experience much comorbidity, ${ }^{13}$ but to what extent that is related to functioning in patients with stroke has not been well explored.

Our main objectives were ( 1 ) to describe the functional status and use of healthcare facilities of long-term $(>10$ year) survivors of a TIA or an MIS and (2) to identify associations with baseline and follow-up characteristics (including comorbidity).

\section{PATIENTS AND METHODS \\ Study population}

LiLAC (Life Long After Cerebral ischemia) is a cohort study based on the cohorts of the Dutch TIA Trial (DTT) and the European Atrial Fibrillation Trial (EAFT). Patients who had had a TIA or an MIS were included in these trials. A neurologist in one of the participating hospitals made the diagnosis. For participation in the trials, the TIA (symptoms lasting for $<24 \mathrm{~h}$ ) or MIS (symptoms persisting for $>24 \mathrm{~h}$ ) had to have occurred within 3 months before randomisation and patients had to be independent in most of their daily activities $(\mathrm{mRS} \leqslant 3)$. Details have been described previously. ${ }^{14}$ is In the DTT, 3150 patients were included; a cardiac or haematological origin of the ischaemic event was

Abbreviations: DTT, Dutch TIA Trial; EAFT, European Atrial Fibrillation Trial; FAl, Frenchay Activities Index; LiLAC, Life Long After Cerebral ischemia; MIS, minor ischaemic stroke; mRS, (modified) Rankin Scale; TIA, transient ischaemic attack 
an exclusion criterion. For LiLAC we included patients from centres that had randomised $\geqslant 50$ patients $(n=2473)$. In the EAFT, 1007 patients were included; current ( $<2$ years) atrial fibrillation (confirmed by electrocardiography) was a prerequisite. For LiLAC we included only the Dutch participants $(\mathrm{n}=186)$.

In the current study, the follow-up of all patients alive at the end of the DTT and EAFT was extended to the period between March 2001 and December 2003: 1024 patients survived. With a computer-generated list, we contacted a random sample of survivors to administer the postal questionnaire, aiming at 500 completed ones. From the responders to the questionnaire, we drew another random sample (aiming at 200 participants) for a home visit to get more detailed information about the functional status. All patients gave written informed consent. The ethics committee of the University Medical Centre Utrecht, The Netherlands, approved the protocol.

\section{Measurements}

Baseline characteristics (medical history, event characteristics and data from electrocardiograms and computed tomography) were thoroughly recorded in both trials. Information on recurrence of stroke was captured from medical records or from the general practitioner of the patients. All reported strokes were classified independently by three doctors specialised in cerebrovascular disease, according to the criteria previously used in the DTT and EAFT. For any doubt on the classification or if the adjudicators did not reach an agreement, members of the executive committee of the European/Australian Stroke Prevention in Reversible Ischaemia Trial (a currently running multicentre secondary prevention trial in patients with cerebral ischaemia of arterial origin $)^{16}$ were consulted.

In the structured interview of the postal questionnaire, information about living condition (alone or with partner, independent or protected) was gathered. Comorbidity was assessed on a predefined structured list comprising a broad range of diseases in the following categories: cardiac, respiratory, diabetes, neurological, locomotor system, cancer, ocular system, auditory system or others (see appendix provided online at http://www.jnnp.com/supplemental). The list was composed on the basis of a known or assumed high burden of illness. ${ }^{17}$ Patients also had to state whether they still received drugs or treatment for this additional disease and whether it influenced their daily functioning.

Standardised tests to evaluate functioning included the Barthel Index and the Frenchay Activities Index (FAI). The Barthel Index is a widely used and validated instrument for outcome measurements. ${ }^{18}$ Scores are in the range $0-20$, with 20 representing independence within the home, but not necessarily normal functioning. The FAI is a sensitive, reliable and valid instrument for assessing social activity or participation. ${ }^{19}$ It supplements the Barthel Index in activities of daily life, with minimal overlap. ${ }^{20}$ It is based on an interview with patients and has no ceiling effect. ${ }^{19}$ Both instruments have an excellent proxy agreement. ${ }^{21}$ Scores on the FAI are in the range 15-60, and can be divided into three categories: 15-29, inactive; 30-44, active; and 45-60, very active. The mRS is a handicap scale that has been used before in both trials, at baseline and during follow-up. ${ }^{22}$ It can be considered to be a global health index, with a strong emphasis on physical activity, ${ }^{5}$ with 0 indicating no symptoms and 5 indicating total dependence.

We assessed the use of healthcare facilities according to two previous studies. ${ }^{23}$ For this purpose, we aggregated professional care into four categories: (a) therapy, including physical therapy, occupational therapy and speech therapy; (b) (instrumental) care of activities of daily living, including day care, nursing care and home help; (c) psychosocial support, including social care, mental care and support from fellow patients; and (d) aids, including adaptation of home, non-body-adapted and body-adapted aids, and aids to promote outdoor mobility.

\section{Data analysis}

Data were analysed to describe the long-term functional status and use of healthcare facilities by stroke survivors. Therefore, descriptive statistics (parametric and non-parametric) were used according to the characteristics of the measurement instruments. Data were analysed by logistic regression to identify associations of baseline and follow-up characteristics with the different functional outcomes: independence (Barthel Index $=20)^{24}$ versus dependence $($ Barthel Index $<20)$ in daily activities; inactive (FAI 15-29) versus active $(F A I \geqslant 30)$ lifestyles; no or mild handicap $(\mathrm{mRS} \leqslant 2)$ versus moderate or severe handicap $(\mathrm{mRS}>2)$; and use of professional care (yes or no; use of at least one type of professional care, excluding the use of aids or assistive devices). Results were presented as odds ratios (ORs), including 95\% confidence intervals (CIs). In multivariate analyses, variables were selected (stepwise forward) until no variable had $\mathrm{p}<0.10$. Healthcare facilities were analysed with data only from home visits, and data on patients who were institutionalised were not taken into account.

\section{RESULTS}

Of the 1024 survivors of the original trials, 838 were sent a questionnaire (fig 1). Of these, 468 agreed to participate, 126 refused, 39 had died and 205 did not respond. Those who did not respond, died or refused participation were older $(61.6 \mathrm{v}$

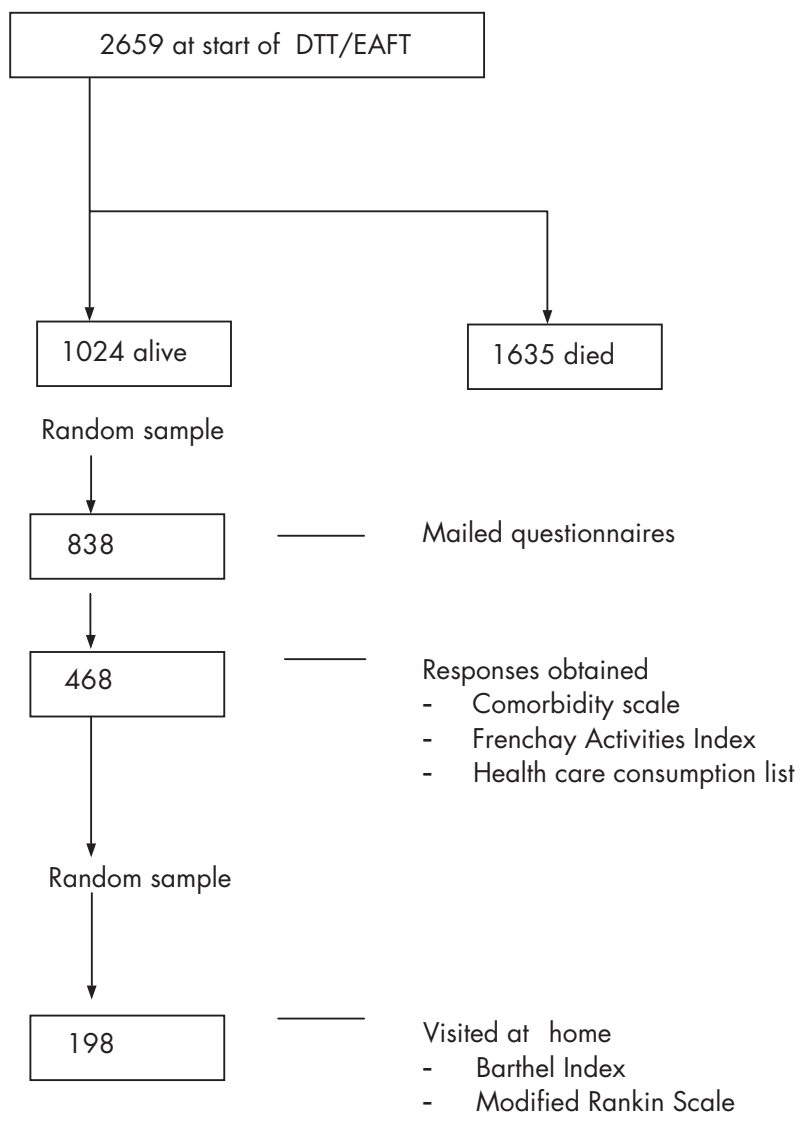

Figure 1 Flow chart of participants analysed. BI, Barthel Index; DTT Dutch TIA Trial; EAFT, European Atrial Fibrillation Trial; FAI, Frenchay Activities Index; mRS, (modified) Rankin Scale. 
Table 1 Characteristics of different patient groups

\begin{tabular}{|c|c|c|c|}
\hline Characteristic & $\begin{array}{l}\text { Total } \\
(n=2659)\end{array}$ & $\begin{array}{l}\text { Postal } \\
\text { questionnaire } \\
\text { ( } n=468 \text { ) }\end{array}$ & $\begin{array}{l}\text { Home visits } \\
\text { ( } n=198)\end{array}$ \\
\hline \multicolumn{4}{|l|}{ At baseline } \\
\hline Women & 35.5 & 34.6 & 32.3 \\
\hline $\begin{array}{l}\text { Mean (SD) age at } \\
\text { randomisation (years) }\end{array}$ & $65.8(10.1)$ & $57.1(9.3)$ & $56.9(8.8)$ \\
\hline MIS $v$ TIA & 69.8 & 57.7 & 57.1 \\
\hline Diabetes & 8.3 & 3.2 & 3.5 \\
\hline Intermittent claudication & 5.1 & 2.0 & 2.0 \\
\hline Hypertension & 42.1 & 33.3 & 34.8 \\
\hline $\begin{array}{l}\text { Myocardial infarction } \\
\text { Grade on mRS }\end{array}$ & 10.4 & 6.0 & 7.1 \\
\hline 0 & 45.0 & 58.8 & 58.1 \\
\hline 1 & 30.7 & 26.9 & 28.3 \\
\hline 2 & 18.8 & 11.8 & 12.1 \\
\hline 3 & 5.4 & 2.6 & 1.5 \\
\hline Any infarct on $C T$ scan & 41.4 & 30.1 & 25.3 \\
\hline $\begin{array}{l}\text { White matter lesions } \\
\text { At follow-up }\end{array}$ & 11.6 & 2.8 & 2.0 \\
\hline New vascular event & 55.4 & 18.2 & 26.3 \\
\hline $\begin{array}{l}\text { Mean (SD) age at } \\
\text { home visit (years) }\end{array}$ & NA & NA & $72.5(8.7)$ \\
\hline \multicolumn{4}{|c|}{$\begin{array}{l}\text { Values are percentages unless otherwise mentioned. } \\
\text { CT, computed tomography; MIS, minor ischaemic attack; mRS, } \\
\text { (modified) Rankin Scale; NA, not available; TIA, transient ischaemic } \\
\text { attack. }\end{array}$} \\
\hline
\end{tabular}

57.1 years), more often women $(41.1 \% \vee 34.6 \%)$, had more often an MIS rather than a TIA $(63.8 \% v 57.7 \%)$ or showed white matter lesions on the computed tomography scan at baseline $(6.5 \% \vee 2.8 \%)$. Data for the postal questionnaires were missing in $6 \%$ for some comorbidity items and in $15 \%$ for the FAI. A random sample of participants $(n=198)$ was contacted for a home visit (fig l).

\section{Demographics and comorbidity}

The mean age of patients at the time of the home visit was 72.5 (SD 8.7) years. Patients who participated in the survey or home visit were younger, had more often a TIA rather than an ischaemic stroke and had fewer vascular risk factors at baseline than the average participant of the LiLAC study (table 1).

After a mean follow-up of 15.6 (SD 1.1) years, only 5-7\% of the responding survivors were institutionalised and most were living with a partner (table 2).

Patients recalled several comorbid conditions, mostly of the heart or locomotor system. Of the 147 patients who reported concomitant disease, 144 answered the question "Which one of the above diseases has the greatest impact on your daily functioning?" Locomotion was mentioned most often (25\%, 36/144).

\section{Functional status and disability}

The median Barthel Index was 20, but a third of the patients was dependent in one or more activities of daily living. About $18 \%$ of patients presented an inactive lifestyle $(\mathrm{FAI}<29)$ and $26 \%$ were moderately to severely handicapped (mRS $>3$; fig 2 ). The mRS deteriorated significantly over time (median -1 , range -4 to $+2 ; \mathrm{p}<0.001$ )

Advanced age and the presence of any infarct on a computed tomography scan at baseline, and a recurrent stroke or the presence of comorbidity of locomotion, were strongly and independently associated with functional disability, inactivity and handicap (table 3 ).

We found no statistically significant relationship between the use of secondary preventive drugs (at follow-up) and functional status.
Table 2 Descriptive statistics of demographic characteristics, comorbidity, functional status and use of healthcare facilities

\begin{tabular}{|c|c|c|}
\hline & $\begin{array}{l}\text { Postal } \\
\text { questionnaire } \\
\text { ( } n=468 \text { ) }\end{array}$ & $\begin{array}{l}\text { Home visit } \\
(n=198)\end{array}$ \\
\hline \multicolumn{3}{|l|}{ Living condition } \\
\hline Independent & 93.4 & 94.9 \\
\hline Institutionalised & 6.6 & 5.1 \\
\hline \multicolumn{3}{|l|}{ Living situation } \\
\hline With partner or other & 68.7 & 69.1 \\
\hline Alone & 31.3 & 30.9 \\
\hline \multicolumn{3}{|l|}{ Comorbidity } \\
\hline Cardiac & 35.7 & 36.4 \\
\hline Respiratory & 14.7 & 17.2 \\
\hline Diabetes & 16.8 & 16.2 \\
\hline Neurological* & 10.6 & 12.1 \\
\hline Locomotion & 35.7 & 37.6 \\
\hline Cancer & 7.7 & 3.5 \\
\hline Visual & 10.7 & 10.1 \\
\hline Auditive & 14.1 & 15.7 \\
\hline Other & 22.9 & 18.2 \\
\hline \multicolumn{3}{|l|}{ Functional status } \\
\hline BI (median, IQR) & NA & $20(19-20)$ \\
\hline Independent & & 67.2 \\
\hline Dependent & & 32.8 \\
\hline FAI (median, IQR) & $41(33-46)$ & $41(34-46)$ \\
\hline Inactive & 18.1 & 17.9 \\
\hline Active & 47.7 & 50.0 \\
\hline Very active & 34.2 & 32.1 \\
\hline mRS (median, IQR) & NA & $1(1-3)$ \\
\hline 0 & & 19.2 \\
\hline 1 & & 34.8 \\
\hline 2 & & 20.2 \\
\hline 3 & & 22.2 \\
\hline 4 & & 3.5 \\
\hline \multicolumn{3}{|l|}{ Use of drugs } \\
\hline Aspirin & 65.2 & 67.0 \\
\hline Anticoagulants & 15.5 & 11.7 \\
\hline Other & 9.5 & 11.2 \\
\hline None & 9.8 & 10.1 \\
\hline \multicolumn{3}{|l|}{ Use of healthcare facilities } \\
\hline Treatment & 19.1 & 18.1 \\
\hline ADL care & 26.4 & 19.3 \\
\hline Psychosocial care & 3.2 & 1.2 \\
\hline Adjustments & 32.3 & 28.2 \\
\hline
\end{tabular}

Values are percentages unless otherwise mentioned. $A D L$, activities of daily living; $B I$, Barthel Index; FAl, Frenchay Activities Index; IQR, interquartile range; mRS, (modified) Rankin Scale; NA, not available, measurement was part of interview at home visit only. *Only diseases other than transient ischaemic attack or stroke were counted.

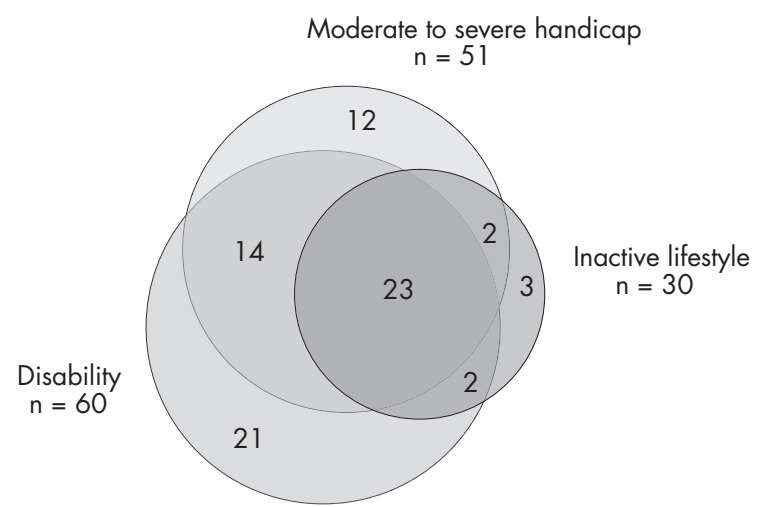

Disability $=$ Barthel Index $<20$; Inactive lifestyle $=$ Frenchay Activities Index < 30; moderate to severe handicap = Modified Rankin Scale $>2$.

Figure 2 Venn diagram of disability, inactivity and handicap. Disability, Barthel Index $<20$; inactive lifestyle, Frenchay Activities Index $<30$; moderate to severe handicap, modified Rankin Scale $>2$. 
Table 3 Associations with functional disability and handicap

\begin{tabular}{|c|c|c|c|}
\hline $\begin{array}{l}\text { Patients } \\
\mathrm{n}=198\end{array}$ & $\begin{array}{l}\text { Dependency } \\
\text { in ADL } \\
(B \mid<20) \\
O R(95 \% \mathrm{Cl})\end{array}$ & $\begin{array}{l}\text { Inactive } \\
\text { lifestyle } \\
\text { (FAl }<30) \\
\text { OR (95\% CI) }\end{array}$ & $\begin{array}{l}\text { Moderate or severe } \\
\text { handicap } \\
\text { (mRS }>2) \\
\text { OR }(95 \% \mathrm{Cl})\end{array}$ \\
\hline \multicolumn{4}{|l|}{ Univariate regression } \\
\hline $\mathrm{Age}^{*}+$ & $1.9(1.3$ to 2.8$)$ & $1.8(1.1$ to 2.9$)$ & 1.8 (1.2 to 2.7$)$ \\
\hline Male sex $†$ & $0.6(0.3$ to 1.2$)$ & $1.2(0.5$ to 2.8$)$ & $0.5(0.3$ to 1.0$)$ \\
\hline Minor stroke† & 1.5 (0.8 to 2.8$)$ & $2.9(1.1$ to 7.3$)$ & $2.0(1.0$ to 4.0$)$ \\
\hline Any infarct on CT scant & $2.6(1.3$ to 5.3$)$ & $8.9(3.6$ to 21.6$)$ & 5.8 (2.7 to 12.5$)$ \\
\hline New VE $\ddagger$ & $2.9(1.4$ to 6.0$)$ & $4.8(2.0$ to 11.5$)$ & 3.8 (1.8 to 8.3$)$ \\
\hline Recurrent major stroke $\ddagger$ & $4.6(2.0$ to 10.8$)$ & $9.3(3.6$ to 23.8$)$ & 5.6 (2.3 to 13.5$)$ \\
\hline Comorbidity locomotionf & $2.2(1.2$ to 4.3$)$ & $1.8(0.8$ to 4.0$)$ & 4.7 (2.3 to 9.7$)$ \\
\hline Comorbidity cardiacf & $1.3(0.7$ to 2.5$)$ & $1.8(0.8$ to 4.1$)$ & $1.8(0.9$ to 3.6$)$ \\
\hline \multicolumn{4}{|l|}{ Multivariate regression } \\
\hline $\mathrm{Age}^{*} \dagger$ & 2.2 (1.4 to 3.5$)$ & $2.3(1.3$ to 4.1$)$ & 2.6 (1.5 to 4.4$)$ \\
\hline Minor stroke† & & $1.6(0.5$ to 4.6$)$ & \\
\hline Any infarct on CT scant & $2.9(1.3$ to 6.3$)$ & 7.3 (2.8 to 19.5$)$ & $7.3(2.8$ to 19.0$)$ \\
\hline Recurrent major strokef & $5.4(2.2$ to 12.9$)$ & $8.0(2.9$ to 22.2$)$ & $7.0(2.5$ to 19.4$)$ \\
\hline Comorbidity locomotion $\ddagger$ & $3.2(1.6$ to 6.7$)$ & NE & $8.9(3.6$ to 22.1$)$ \\
\hline \multicolumn{4}{|c|}{$\begin{array}{l}\text { Values are odds ratios ( } 95 \% \text { confidence intervals). } \\
\text { ADL, activities of daily living; BI, Barthel Index; CT, computed tomography; FAl, Frenchay Activities Index; mRS } \\
\text { (modified) Rankin Scale; NE, variable not entered in the multivariate analysis; OR, odds ratio; VE, vascular event } \\
\text { All variables in the univariate analysis were adjusted for sex and age. } \\
\text { *Age was entered as a continuous variable; the increase in hazard is for every } 10 \text { years. } \\
\text { tVariable was measured at baseline. } \\
\text { fVariable was measured during follow-up. }\end{array}$} \\
\hline
\end{tabular}

In the analyses on dependency, we used a cut-off of 2 on the mRS, whereas a cut-off of 3 was chosen as a selection criterion for the original trials. Exclusion of patients with a baseline mRS of 3 did not change the results.

\section{Use of healthcare facilities}

About $65 \%$ of the survivors were still using aspirin and 16\% anticoagulant drugs, whereas $10 \%$ did not use any kind of drug as secondary prevention (table 2 ).

Only $31 \%$ of survivors currently used any kind of professional care. In the univariate analysis, advanced age, an MIS at baseline (rather than a TIA), functional disability and handicap at follow-up were associated with the use of professional care (table 4). The strongest relationship was found between handicap at follow-up and the use of adjustments (see table B provided online at http:// www.jnnp.com/supplemental). Dependency in activities of daily living was most strongly related in the multivariate model.

\section{DISCUSSION}

After an average interval of 15.6 years, 33\% of our surviving patients who were visited at home were dependent in one or more daily activities, $18 \%$ had an inactive lifestyle and $26 \%$ were moderately to severely handicapped (fig 2). Factors independently associated with long-term functional disability were advanced age, the presence of any infarct on a computed tomography scan at baseline, the recurrence of a new major stroke and the presence of comorbidity of locomotion. The use of professional care was predominantly related to functional disability and handicap at follow-up.

We described the functional status of our population from the perspectives of doctors (disability) and healthcare providers (use of healthcare facilities). We assessed both basic and

\begin{tabular}{|c|c|c|}
\hline $\begin{array}{l}\text { Patients } \\
n=187\end{array}$ & $\begin{array}{l}\text { Univariate } \\
\text { OR }(95 \% \mathrm{Cl})\end{array}$ & $\begin{array}{l}\text { Multivariate } \\
\text { OR }(95 \% \mathrm{Cl})\end{array}$ \\
\hline $\begin{array}{l}\text { Age }^{*} \dagger \\
\text { Male sext }\end{array}$ & $\begin{array}{l}1.6(1.1 \text { to } 2.4) \\
0.7(0.3 \text { to } 1.4)\end{array}$ & 1.5 (1.0 to 2.3$)$ \\
\hline Minor stroke† & $2.2(1.1$ to 4.3$)$ & $2.0(1.0$ to 4.0$)$ \\
\hline Any infarct on CT scant & $1.2(0.6$ to 2.5$)$ & \\
\hline New VE $\ddagger$ & $1.2(0.6$ to 2.6$)$ & \\
\hline Recurrent major stroke $\ddagger$ & $1.7(0.7$ to 3.8$)$ & \\
\hline Living with partnerł & $0.9(0.4$ to 1.7$)$ & \\
\hline Dependency in ADL $(B \mid<20)$ & $4.0(2.0$ to 8.0$)$ & $2.7(1.2$ to 5.9$)$ \\
\hline Moderate to severe handicap (mRS $>2$ ) & $4.0(1.9$ to 8.4$)$ & $2.4(1.0$ to 5.6$)$ \\
\hline Comorbidity locomotion $\ddagger$ & $1.8(0.9$ to 3.6$)$ & \\
\hline Comorbidity cardiacł & $1.0(0.5$ to 1.9$)$ & \\
\hline
\end{tabular}

Values are odds ratios ( $95 \%$ confidence intervals).

$\mathrm{ADL}$, activities of daily living; BI, Barthel Index; $\mathrm{CT}$, computed tomography; mRS, (modified) Rankin Scale; VE, vascular event.

All variables in the univariate analysis were adjusted for sex and age.

${ }^{*}$ Age was entered as a continuous variable; the increase in hazard is for every 10 years.

Only variables that were significant $(p<0.05)$ in the univariate analysis were entered in the multivariate analysis. †Variable was measured at baseline.

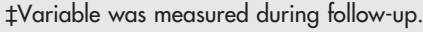


instrumental activities of daily living and used standardised instruments for measurement; this enhanced interpretation and allowed for comparison with other studies. In addition, we studied associations between outcome and characteristics at baseline and at follow-up (including comorbidity).

A potential limitation in the interpretation of our results was that we were dealing with a highly selected cohort of patients, in that they (a) were referred to hospital, (b) consented to participate in a trial, (c) survived for an average of about 15 years, and (d) consented to participate in the survey and home visit. Although the characteristics of survivors who participated in the survey and home visit did not differ much in baseline cardiovascular risk factors from those who declined, they probably represent the fittest of those surviving. We were not able to record all reasons for non-response; possibly cognitive impairment or depression had a role, with a negative effect on outcome. The main implication of this selection is that the amount of disability and use of professional care are probably underestimated.

We also had to deal with missing data, which is a common phenomenon with postal questionnaires in an elderly population: this may have introduced bias.

The comparison of our results with those from other studies on long-term (at least 5 years) functioning after stroke was complicated because no other study included patients with a TIA, and all but one were community based. $^{810-122526}$ Details about other differences in study design or population are presented in table A, provided online at http://www.jnnp.com/supplemental. Only a single study investigated prognostic factors for disability ${ }^{26}$ and most studies did not report data on non-responders. Only $5 \%$ of our population was institutionalised compared with $8 \%,{ }^{27}$ $15 \%^{10}{ }^{26}$ and $23 \%{ }^{12}$ in other studies. The $10 \%$ of patients who did not use any kind of secondary prevention with drugs is remarkably low.

The proportion of patients dependent in activities of daily living (Barthel Index $<20$ ) in our study was almost half that of a study in southeast London ${ }^{27}(34 \% v 67 \%)$, probably as a result of younger age and inclusion of less severe types of stroke in our population. Also, the proportion of patients with mRS $>2$ was smaller than in studies from the general population (26\% v 36-64\%). ${ }^{86}{ }^{27}$ Advanced age and recurrent stroke were predictors of long-term disability ( 5 years) this was also the case in the Perth Community Stroke Study. ${ }^{26}$ Although it is not surprising that there is a relationship between comorbidity of locomotion and dependency, this has not been described so clearly in patients with stroke before. Only a single study on long-term functioning after stroke described the presence of comorbidity in their survivors, but they did not investigate its effect on functional status. ${ }^{10}$

The use of professional care was higher than the $20-25 \%$ reported in two Finnish regions. ${ }^{1026}$ No comparable data are available for the Dutch elderly population. Our data do not provide information on the (unmet) care demands of the long-term survivors of stroke, which would be helpful in planning strategies; as $70 \%$ of the survivors were living with a partner, a certain amount of informal care must have been provided as well.

In a previous study, we found that even long after a TIA or an MIS, patients continue to have an increased risk of death and new vascular events. Their doctors should therefore stay alert regarding lifestyle and drug compliance. ${ }^{1}$ In the present study, we found that the functional status of those who survive is influenced by the occurrence of new vascular events (especially stroke) and by coexisting diseases (mainly of the locomotor system). As the use of professional care was related with the amount of disability or handicap, irrespective of underlying causes, we conclude that there is a need for measuring comorbidity with regard to long-term functional status in future research on stroke outcome. Moreover, the prevention of recurrent stroke may reduce the long-term burden of the elderly patient with a history of a TIA or an MIS. Finally, the focus on comorbidity with regard to stroke may improve the planning and providing of healthcare for those in need.

\section{ACKNOWLEDGEMENTS}

We thank Marrit van Buuren, Moniek Boekweit and Martijn Pruissen for conducting the interviews at patients' homes; Dorien SlabbersBouwman for data entry; and Patricia Halkes for her help with the Venn diagram.

\section{Authors' affiliations}

I van Wijk, L J Kappelle, J van Gijn, A Algra, Department of Neurology, Rudolf Magnus Institute of Neuroscience, University Medical Centre Utrecht, Utrecht, The Netherlands

E Lindeman, J W Gorter, Department of Rehabilitation, University Medical Centre Utrecht; Rehabilitation Centre De Hoogstraat, Utrecht

P J Koudstaal, Department of Neurology, Erasmus Medical Centre, Rotterdam, The Netherlands

Funding: This study was funded by The Netherlands Heart Foundation (99.160) and the "Hersenstichting Nederland" (10F02.14).

Competing interests: None.

The investigators for the Dutch TIA Trial (neurologists of centres with $\geqslant 50$ patients) are listed in the appendix in N Engl J Med 1990;325:1260. The investigators from the Dutch centres of the European Atrial Fibrillation Trial are listed in the appendix in Lancet 1993;342:1262.

Ethical approval: The ethics committee of the University Medical Centre Utrecht, The Netherlands, approved the protocol.

\section{REFERENCES}

1 van Wijk I, Kappelle $U$, van Gijn J, et al. Long-term survival and vascular event risk after transient ischaemic attack or minor ischaemic stroke: a cohort study. Lancet 2005;365:2098-104.

2 Clark TG, Murphy MFG, Rothwell PM. Long term risk of stroke, myocardial infarction, and vascular death in "low risk" patients with a non-recent transient ischaemic attack. J Neurol Neurosurg Psychiatry 2003;74:577-80.

3 Prencipe $M$, Culasso F, Rasura $M$, et al. Long-term prognosis after a minor stroke. 10-year mortality and major stroke recurrence rates in a hospitalbased cohort. Stroke 1998;29:126-32.

4 Staaf G, Lindgren A, Norrving B. Pure motor stroke from presumed lacunar infarct. Long-term prognosis for survival and risk of recurrent stroke. Stroke 2001;32:2592-6.

5 de Haan RJ, Limburg M, Bossuyt $P$, et al. The clinical meaning of Rankin 'handicap' grades after stroke. Stroke 1995;26:2027-30.

6 Scholte op Reimer WJM. Unmet care demands after stroke: deficits in health care? Qual Health Care 1999:8:30-5.

7 Kappelle $\mathrm{L}$, Adams-HP J, Heffner ML, et al. Prognosis of young adults with ischemic stroke. A long-term follow-up study assessing recurrent vascular events and functional outcome in the lowa Registry of stroke in young adults. Stroke 1994;25:1360-5.

8 Hardie K, Hankey GJ, Jamrozik K, et al. Ten-year risk of first recurrent stroke and disability after first-ever stroke in the Perth Community Stroke Study. Stroke 2004;35:731-5.

9 Scmidt EV, Smirnov VE, Ryabova VS. Results of the seven-year prospective study of stroke patients. Stroke 1988;19:942-9.

10 Tuomilehto J, Nuottimaki T, Salmi K, et al. Psychosocial and health status in stroke survivors after 14 years. Stroke 1995;26:971-5.

11 Anderson CS, Carter KN, Brownlee WJ, et al. Very long-term outcome after stroke in Auckland, New Zealand. Stroke 2004;35:1920-4

12 Hackett ML, Duncan JR, Anderson CS, et al. Health-related quality of life among long-term survivors of stroke: results from the Auckland Stroke Study, 1991-1992. Stroke 2000;31:440-7.

13 Liu M, Tsuji T, Tsujiuchi K, et al. Comorbidities in stroke patients as assessed with a newly developed comorbidity scale. Am J Phys Med Rehabil 1999;78:416-24.

14 The Dutch TIA Trial Study Group. A comparison of two doses of aspirin (30 mg vs. $283 \mathrm{mg}$ a day) in patients after a transient ischemic attack or minor ischemic stroke. N Engl J Med 1991;325:1261-6.

15 EAFT (European Atrial Fibrillation Trial) Study Group. Secondary prevention in non-rheumatic atrial fibrillation after transient ischaemic attack or minor stroke. Lancet 1993;342:1255-62.

16 De Schryver EL, on behalf of the European/Australian Stroke Prevention in Reversible Ischaemia Trial Study Group. Design of ESPRIT: an international randomized trial for secondary prevention after non-disabling cerebral ischaemia of arterial origin. Cerebrovasc Dis 2000;10:147-50.

17 Bos GAMvd. The burden of chronic diseases in terms of disability, use of health care and healthy life expectancies. Eur J Public Health 1995;5:29-34. 
18 Wade DT, Langton HR. Functional abilities after stroke: measurement, natural history and prognosis. J Neurol Neurosurg Psychiatry 1987;50:177-82.

19 Schuling J, Haan Rd, Limburg M, et al. The Frenchay Activities Index. Assessment of functional status in stroke patients. Stroke 1993;24:1173-7.

20 Pedersen PM, Jorgensen HS, Nakayama H, et al. Comprehensive assessment of activities of daily living in stroke. The Copenhagen Stroke Study. Arch Phys Med Rehabil 1997;78:161-5.

21 Segal ME, Schall RR. Determining functional/health status and its relation to disability in stroke survivors. Stroke 1994;25:2391-7.

22 Bamford JM, Sandercock PA, Warlow CP, et al. Interobserver agreement for the assessment of handicap in stroke patients [letter]. Stroke $1989 ; 20: 828$.
23 de Haan RJ, Limburg M, van der Meulen JHP, et al. Use of health care services after stroke. Qual Health Care 1993;2:222-7.

24 Keith RA. Functional status and health status. Arch Phys Med Rehabil 1994:75:478-83

25 Gresham GE, Kelly-Hayes M, Wolf PA, et al. Survival and functional status 20 or more years after first stroke: the Framingham Study. Stroke 1998;29:793-7.

26 Hankey GJ, Jamrozik K, Broadhurst RJ, et al. Long-term disability after firstever stroke and related prognostic factors in the Perth Community Stroke Study, 1989-1990. Stroke 2002;33:1034-40.

27 Wilkinson PR, Wolfe CD, Warburton FG, et al. A long-term follow-up of stroke patients. Stroke 1997;28:507-12.

\section{NEUROLOGICAL PICTURE}

\section{Intracranial calcifications and activating mutation of the calcium-sensing receptor}

A 58-year-old man was referred to us because of asymptomatic hypocalcaemia (calcium $6.5 \mathrm{mg} / \mathrm{dl}$, normal range 8.5-10.4). The patient had one healthy son and two daughters with hypocalcaemia. Analytical study confirmed hypocalcaemia (ionised calcium $0.86 \mathrm{nmol} / \mathrm{l}$, normal range 1.13-1.32), which was accompanied by low levels of intact parathyroid hormone $(19 \mathrm{pg} / \mathrm{ml}$, normal $<65$ ). Serum phosphorus, 25-hydroxyvitamin D and 1,25dihydroxyvitamin D were within normal range. Hypocalcaemia was associated with hypercalciuria when oral calcium and vitamin D were administered. Gene study showed a novel activating mutation (Glu(604)Lys) affecting the calcium-sensing receptor in the patient and his two daughters. Morphological studies of the patient showed multiple intracranial calcifications affecting the basal ganglia, cerebellum and brain parenchyma (figs 1, 2). We think that activating mutations of CaSR should be considered as a new cause of hypocalcaemia-induced asymptomatic intracranial calcifications.

Department of Endocrinology, Hospital General, Segovia, Spain

J J Díez

Hospital Ramón y Cajal, Madrid, Spain

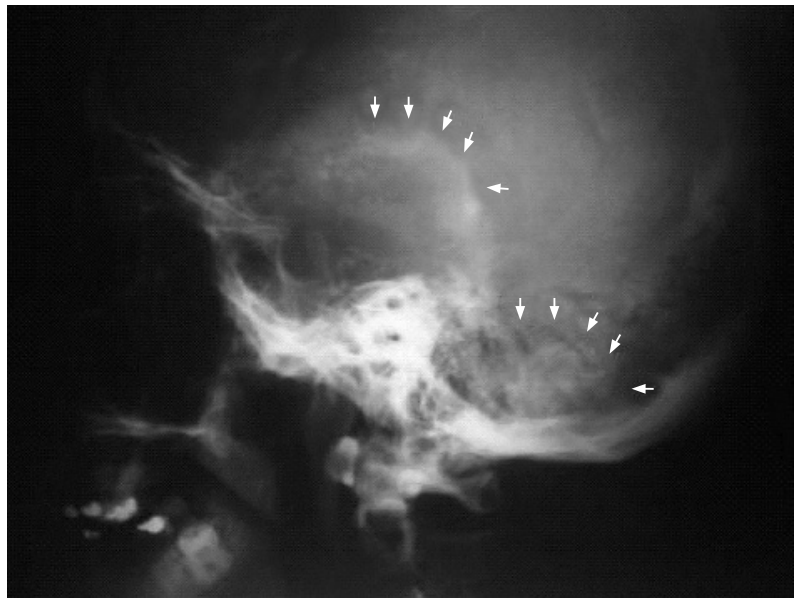

Figure 1 Lateral radiography of the cranium showing basal ganglia and cerebellar calcifications.

Correspondence to: P. Iglesias, Department of Endocrinology, Hospital General, ctra de Avila s/n, Segovia 40002, Spain; piglesias@hgse.sacyl.es

Competing interests: None declared.
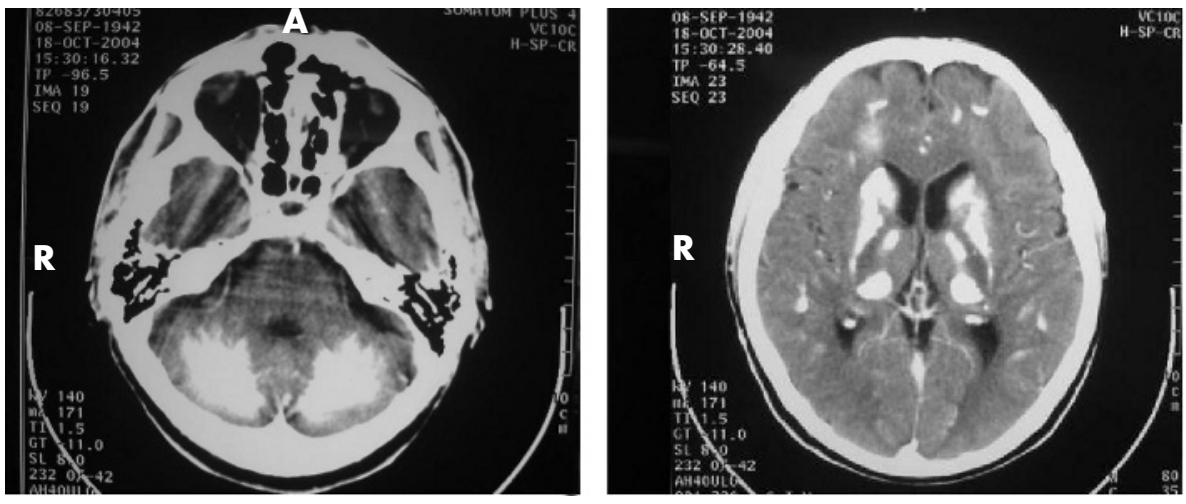

Figure 2 Computed tomography images of the brain showing multiple calcifications of the cerebellum (leff), basal ganglia and brain parenchyma (right). 